\title{
Biodiversity of lactococcal bacteriophages isolated from 3 Gouda-type cheese-producing plants
}

\author{
James Murphy, ${ }^{*}$ Bridget Royer, ${ }^{*}$ Jennifer Mahony, ${ }^{*}$ Lesley Hoyles, ${ }^{*}$ Knut Heller, $\dagger$ Horst Neve, $\dagger$ \\ Martin Bonestroo, $\ddagger$ Arjen Nauta, $\ddagger$ and Douwe van Sinderen* $\S^{1}$ \\ *Department of Microbiology, University College Cork, Cork, Ireland \\ †Department of Microbiology and Biotechnology, Max Rubner Institut, Kiel 24103, Germany \\ $\ddagger$ FrieslandCampina, Stationsplein 4, 3818 LE, Amersfoort, the Netherlands \\ §Alimentary Pharmabiotic Centre, University College Cork, Cork, Ireland
}

\begin{abstract}
This study reports on the identification and characterization of bacteriophages isolated from cheeseproduction facilities that use undefined, mixed starter cultures. Phage screening was carried out on whey samples isolated from 3 factories, 2 utilizing one particular undefined starter mixture and 1 utilizing another undefined starter mixture. Phage screening was carried out using 40 strains isolated from the 2 mixed starter cultures, and phages were profiled using host range, electron microscopy, multiplex PCR, and DNA restriction analysis. Twenty distinct lactococcal phages were identified based on host range and DNA restriction profiles, all belonging to the 936-type phage species. Nineteen of these phages were found to be able to infect both recognized subspecies of Lactococcus lactis. Restriction of phage DNA isolated using a newly developed guanidinium thiocyanate disruption method showed that the genomes of the 20 isolated phages were between 26 and $31 \mathrm{~kb}$ in size. It is evident from this study that the use of mixed starters creates an ideal environment for the proliferation of different phages with slightly varying host ranges. Furthermore, in this environment, members of the 936-type phage species clearly dominated the phage population.
\end{abstract}

Key words: lactic acid bacteria, 936-type phage, cheese whey, starter culture

\section{INTRODUCTION}

Bacteriophages (or phages) have been recognized as the main cause of fermentation problems encountered in the dairy industry since they were first discovered by Whitehead and Cox (1935). Strains of Lactococcus lactis are one of the most important and extensively used starter cultures in the dairy fermentation industry

Received March 4, 2013

Accepted April 25, 2013.

${ }^{1}$ Corresponding author: d.vansinderen@ucc.ie and, despite decades of research, many such starter strains continue to suffer from phage attacks (Sing and Klaenhammer, 1993; Garvey et al., 1995; Emond and Moineau, 2007).

The majority of L. lactis-infecting phages isolated from commercial dairy fermentations can be classified into 3 species or types: 936, c2, and P335 (Moineau et al., 1992). Members of the 936 and c2 species represent lytic bacteriophages, with the former possessing a small isometric head and the latter displaying a prolate head. Like 936 phages, P335 phages have a small isometric head, but differ from the other 2 species in that members of the P335 species can be either lytic or temperate. These dominant phages are thought to be introduced into dairy plants via raw milk due to their ability to resist pasteurization (Atamer et al., 2009; Capra et al., 2013), and they have been shown to persist in and spread through the plant by means of airborne particles (Verreault et al., 2011). Furthermore, P335 phages are found to exist as lysogens within lactococcal starter cultures (Kenny et al., 2006), which can subsequently be induced into the processing environment under favorable conditions, leading to starter culture infection. To prevent the negative consequences of phage infection in the dairy factory (i.e., the development of slow or dead vats), various countermeasures are employed, such as strain rotation regimens and the application of isolated bacteriophage-insensitive strains, in addition to chemical sanitizers and thermal treatments to inactivate phages (Quiberoni et al., 2003; Muller-Merbach et al., 2005; Atamer and Hinrichs, 2009; Guglielmotti et al., 2011).

Several studies have been carried out to investigate the prevalence and diversity of phages in dairy plants from various geographical regions. These studies involved phage isolates from Canada (Moineau et al., 1992), Ireland (Casey et al., 1993), Slovenia (Miklič and Rogelj, 2003), Poland (Szczepanska et al., 2007), Germany (Atamer et al., 2009), and Pakistan (Hussain et al., 2008). In addition to representatives of the commonly isolated 936- and c2-type phages, a less 
frequently isolated species was found in dairy facilities in the Republic of Belarus, and shown to belong to the P034 type, which is a member of the Podoviridae family (Raiski and Belyasova, 2009). With just a few exceptions (Moineau et al., 1992; Raiski and Belyasova, 2009), members of the 936-type phage are isolated most frequently from dairy facilities (Mahony et al., 2012). Most recently, a putative 936-type phage was isolated, from a failed Brazilian fermentation, with an estimated genome size of $48 \mathrm{~kb}$, which would represent the largest 936-type phage genome reported to date (Eller et al., 2012). The majority of biodiversity studies have been carried out on facilities using defined starters. In recent years, the genome sequences of many 936- and P335-type phages have become available, providing important information on the functionality, evolution, and genomic lineage of these phages (Mahony et al., 2006; Labrie et al., 2008; Castro-Nallar et al., 2012) that will aid in understanding why these phage species dominate in dairy fermentations. Here we report an extensive characterization of phages isolated from 3 dairy plants located in the Netherlands that utilized 2 undefined multi-strain mixtures of L. lactis ssp. cremoris, ssp. lactis, and ssp. lactis biovar diacetylactis strains in the manufacture of Gouda-type cheese.

\section{MATERIALS AND METHODS}

\section{Bacterial Strains and Phages}

A total of 40 L. lactis strains isolated from 2 undefined starter mixes (L. lactis ssp. cremoris, ssp. lactis, and ssp. lactis biovar diacetylactis) designated A through to $\mathrm{T}$ [isolated from undefined starter mixture (SM)1] and strains 1 through to 20 (isolated from undefined starter mixture SM2; Table 1) used in this study were routinely propagated in $12 \%$ reconstituted skim milk (RSM) or in M17 broth (Oxoid, Basingstoke, UK) supplemented with $0.5 \%$ lactose at $30^{\circ} \mathrm{C}$. Stock cultures were stored in $10 \%$ RSM or $50 \%$ sterile glycerol (Analar grade $80 \%$ vol/vol; Sigma, St. Louis, MO) at $-20^{\circ} \mathrm{C}$ or $-80^{\circ} \mathrm{C}$. The 20 phages used in this study were maintained as lysates at $4^{\circ} \mathrm{C}$ (Table 1 ).

\section{Determination of Individual Strain Isolates}

Over 200 individual strains were isolated from the undefined starter cultures SM1 and SM2 after cultivation of the mixtures under various conditions. On the basis of differences in growth and lysis characteristics, acidification rate and enzyme activity, 40 individual isolates were selected (20 from each starter mixture). To confirm that these isolates were distinctive strains, plasmid profiling of each strain was performed as fol- lows: overnight cultures were centrifuged at $2,700 \times$ $g$ for $10 \mathrm{~min}$, and the resulting pellet was then resuspended in protoplast buffer $(20 \mathrm{~m} M$ Tris- $\mathrm{HCl}, \mathrm{pH} 7.5,5$ $\mathrm{m} M$ EDTA, $0.75 M$ sucrose, $10 \mathrm{mg} / \mathrm{mL}$ lysozyme, and 50 units/mL of mutanolysin; Sigma) and incubated at $37^{\circ} \mathrm{C}$ for $30 \mathrm{~min}$. The sample was centrifuged at 1,700 $\times g$ for 5 min and plasmid preparations were performed using the GeneJET plasmid miniprep kit as described by the manufacturer (Thermo Scientific, Ballycoolin, Dublin, Ireland).

\section{Subspecies and Biovar Determinations}

The subspecies and biovar assignments of the isolated starter cultures from SM1 and SM2 were based on several phenotypic assays as outlined below. Strains IL1403, F7/2, and MG1363 were used as controls (Table 1).

Arginine Broth Assay. The arginine broth assay was performed as described by Harrigan (1998). A 1 -mL aliquot of overnight culture was added to $5 \mathrm{~mL}$ of arginine broth ( $1 \%$ tryptone, $0.5 \%$ yeast extract, $0.1 \%$ glucose, $0.4 \%$ potassium hydrogen phosphate, and $0.6 \%$ L-arginine) and mixed with $1 \mathrm{~mL}$ of Nessler's reagent (14.3\% sodium hydroxide, $5 \%$ red mercuric iodide, and $4 \%$ potassium iodide; Sigma). Strain identification was based on a $\mathrm{pH}$-dependent color change to either yellow (typical of strains belonging to ssp. cremoris) or red/orange (characteristic of ssp. lactis), as strains of L. lactis ssp. lactis are usually capable of arginine metabolism, thereby releasing ammonia, which causes a $\mathrm{pH}$ increase and consequently a color change of the iodide.

Growth at $40^{\circ} \mathrm{C}$ and $4 \% \mathrm{NaCl}$. Isolated cultures were streaked on M17 agar plates supplemented with $0.5 \%$ (wt/vol) lactose and incubated at $40^{\circ} \mathrm{C}$; they were also streaked on M17 agar plates supplemented with $0.5 \%$ (wt/vol) lactose and $4 \% \mathrm{NaCl}$ and incubated at $30^{\circ} \mathrm{C}$. Strain identification was based on presence or absence of colonies following overnight incubation. Lactococcus lactis ssp. lactis strains have the ability to grow under both conditions, in contrast to strains that belong to L. lactis ssp. cremoris (Harrigan, 1998).

Voges-Proskauer Test. To discriminate between L. lactis ssp. lactis and L. lactis ssp. lactis biovar diacetylactis, the Voges-Proskauer test (O'Meara's modification) was used to test for the production of acetylmethylcarbinol from glucose. Following overnight growth of cultures identified as L. lactis ssp. lactis (see above) in $8 \%$ RSM supplemented with $0.5 \%$ (wt/vol) yeast extract at $30^{\circ} \mathrm{C}, 5 \mathrm{~mL}$ of sodium hydroxide (40\%) and $0.1 \%$ creatine (Sigma) was added. The identification of biovar diacetylactis strains was based on the appearance of a rose coloration above the clotted over- 
Table 1. Bacterial cultures of Lactococcus lactis and phages used in this study

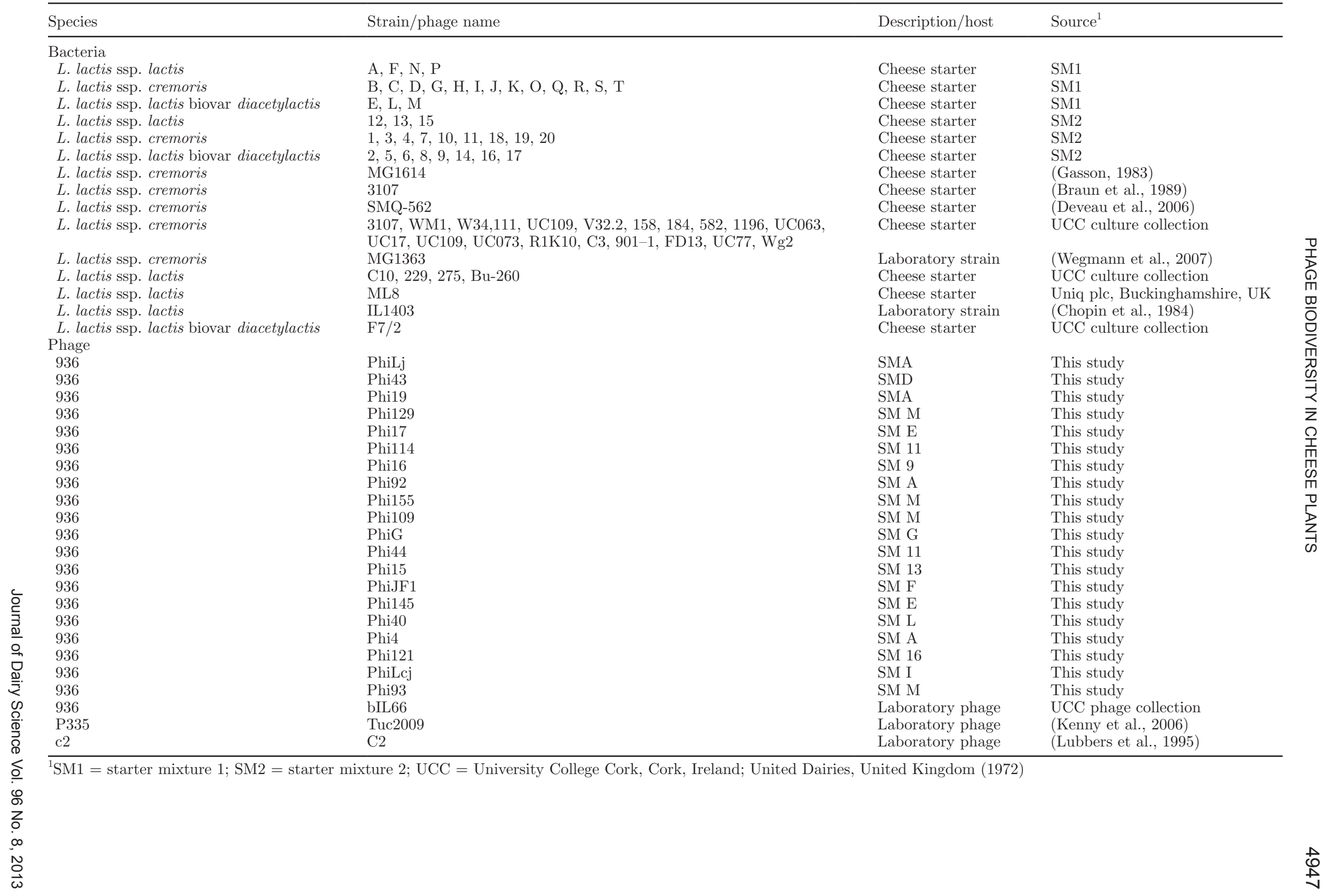


night culture because of the interaction of diacetyl with creatine (Harrigan, 1998).

\section{Bacteriophage Isolation}

Whey samples $(\mathrm{n}=156)$ from 3 Gouda-type cheeseproducing dairy plants were tested for phages against 40 starter cultures isolated from 2 different undefined mixed starter cultures using the double-layer plaque assay method (Lillehaug, 1997), with some modifications: $0.5 \%$ (wt/vol) lactose was incorporated instead of glucose into the M17 plates supplemented with 10 $\mathrm{m} M$ calcium chloride. Following overnight incubation of the plates at $30^{\circ} \mathrm{C}$, phages were enumerated. Propagation of phage was performed on the relevant host strain using individual plaques mixed with a liquid culture of a host at an optical density $\left(\mathrm{OD}_{600}\right)$ of 0.15 to 0.2 with calcium chloride at a final concentration of $10 \mathrm{mM}$. Once lysis had occurred, the lysate (i.e., propagated bacteriophage suspension) was passed through a 0.45$\mu \mathrm{m}$ filter (Sartorius, Ballycoolin, Co. Dublin, Ireland) to remove bacterial cells and cellular debris.

\section{Rapid Phage DNA Extraction and Restriction Analysis}

Phage DNA was isolated using a newly designed method based on a combination of previously published protocols (Chomczynski and Sacchi, 1987; Pillidge and Jarvis, 1988; Reddy et al., 2008) and described below. An equal volume of Phage Disruption Buffer, prepared by the addition of $7.2 \mu \mathrm{L}$ of 2-mercaptoethanol (Sigma) to $1 \mathrm{~mL}$ of GTC stock solution [22.5 $\mathrm{mL}$ of $6 \mathrm{M}$ guanidium thiocyanate solution (Sigma), $6.8 \mathrm{~mL}$ of $\mathrm{H}_{2} \mathrm{O}, 1.76 \mathrm{~mL}$ of sodium citrate, $\mathrm{pH} 7$, and $2.64 \mathrm{~mL}$ of $10 \%$ sarkosyl], was mixed with $60 \mu \mathrm{L}$ of $\mathrm{CsCl}_{2}$ purified phages or $1 \mathrm{~mL}$ of DNase- and RNase-treated bacteriophage lysate $\left[10^{8}\right.$ to $10^{9}$ plaque-forming units $(\mathbf{p f u}) / \mathrm{mL}$ ). Following a 10min incubation at room temperature, an equal volume of phenol:chloroform:isoamyl alcohol (25:24:1; Sigma) was added, mixed, and subjected to centrifugation at $20,800 \times g$ for $5 \mathrm{~min}$. This extraction was repeated, after which DNA present in the aqueous phase was precipitated following the addition of 2.5 volumes of $96 \%$ ice- cold ethanol and 0.1 volume of sodium acetate $(\mathrm{pH}$ 4.8; Sigma), by allowing the mixture to stand for 1 to $2 \mathrm{~min}$, and then collected by centrifugation at $20,800 \times$ $g$ for $15 \mathrm{~min}$. The final pellet was resuspended in 50 to $65 \mu \mathrm{L}$ of Tris-EDTA buffer. Enzyme restriction digests were performed on phage DNA as recommended by the manufacturer (Fermentas, Cambridge, UK).

\section{Multiplex PCR}

Multiplex PCR to perform phage type classification was performed as described previously (Labrie and
Moineau, 2000) using phage lysates, purified phage, or phage DNA as a template. The PCR was run on a TProfessional Basic Gradient PCR machine (Biometra, Goettingen, Germany): $5 \mathrm{~min}$ at $94^{\circ} \mathrm{C}$ followed by 35 cycles $\left(45 \mathrm{~s}\right.$ at $94^{\circ} \mathrm{C}, 1 \mathrm{~min}$ at $58^{\circ} \mathrm{C}, 1 \mathrm{~min}$ at $74^{\circ} \mathrm{C}$ ) and a final step of $5 \mathrm{~min}$ at $74^{\circ} \mathrm{C}$.

\section{Phage Host-Range Determination}

For host-range determination, the phages isolated in this study were propagated on a suitable sensitive host from the industrial starters to a high titer $\left(>10^{8}\right.$ $\mathrm{pfu} / \mathrm{mL}$ ). Spot assays were performed using the doublelayer plaque assay as above and using a wide range of lactococcal strains from both the mixed starter cultures SM1 and SM2, as well as lactococcal strains from the University College Cork (UCC) culture collection (Table 1).

\section{Electron Microscopy}

Purified bacteriophage suspensions obtained from $\mathrm{CsCl}_{2}$ were dialyzed against SM buffer $(50 \mathrm{~m} M$ Tris$\mathrm{HCl}, 100 \mathrm{mM} \mathrm{NaCl}$, and $8 \mathrm{mM}$ magnesium sulfate, $\mathrm{pH}$ 6.5). Staining was performed with $2 \%$ (wt/vol) uranyl acetate on freshly prepared carbon films. Grids were analyzed in a Tecnai 10 transmission electron microscope (FEI Company, Hillsboro, OR) at an acceleration voltage of $80 \mathrm{kV}$. Micrographs were taken with a MegaView II charge-coupled device camera (SIS) at the Max Rubner-Institut (Kiel, Germany; Vegge et al., 2006).

\section{RESULTS}

\section{Isolation and Species Determination of Industrial Starter Strains}

To verify that distinct lactococcal strains had been isolated from each of the 2 undefined starter mixtures SM1 and SM2, plasmid profiles were obtained for each of the 40 isolates (Figure 1). Cheese factories 1 and 2 used SM1, from which strains A to $\mathrm{T}$ were isolated, whereas factory 3 used SM2, from which strains 1 to 20 had been obtained. Each strain was found to exhibit a distinct plasmid profile and the 40 strains were thus regarded as distinct isolates that could be used as hosts for a phage screening effort of whey samples. To assign a subspecies and, where relevant, a biovar distinction to these isolated lactococcal strains, phenotypic assays based on arginine hydrolysis and temperature and $\mathrm{NaCl}$ tolerance were utilized (see Materials and Methods). To further identify ssp. lactis strains that belonged to biovar diacetylactis, diacetyl production was tested. These analyses showed that the 40 strains consisted of 
7 ssp. lactis, 22 ssp. cremoris, and 11 ssp. lactis biovar diacetylactis strains (Table 1 ).

\section{Isolation and Propagation of Phage Isolates}

Phage screening was carried out on 156 whey samples obtained during cheese production (2009-2010 production season) in 3 dairy plants using spot assays against the 40 strains that had been isolated from the 2 undefined starter mixes used in these factories. This survey demonstrated that the proportion of whey samples that tested positive for phage (with phage titers ranging from $10^{3}$ to $10^{8} \mathrm{pfu} / \mathrm{mL}$ ) was $50 \%$ in factory $1,20 \%$ in factory 2 , and $80 \%$ in factory 3 (Figure 2). An individual plaque was subsequently propagated from each positive whey sample on the respective sensitive strain for further analysis. For certain samples, more than one strain was infected. As a result, plaques were propagated for each strain as well as plaques with different morphology. This was to account for the possibility that different phages were present in a single sample.

\section{Identification of Individual Phages Using Genome Restriction Analysis}

To verify the isolation of individual phages from the propagated lysates, restriction endonuclease digestions were carried out on isolated phage DNA to compare the generated restriction profiles using EcoRV and $E c o$ RI. From the propagated phages, 20 distinct restriction patterns (Figure $3 \mathrm{~A}$ and $3 \mathrm{~B}$ ) were observed. One representative phage from each of these 20 restriction profiles was selected for further analysis. Of these 20 phages, 7 were isolated from factory 1, 6 from factory 2 , and 7 from factory 3 . Furthermore, the use of 2 enzymes allowed us to estimate the genome size of each phage, which was found to range between approximately 26 and $31 \mathrm{~kb}$ (phage names and relevant information are provided in Table 2).

\section{Multiplex PCR}

To determine the type of the isolated phages, multiplex PCR was performed on each of the phage lysates as well as on isolated phage DNA. All 20 isolated phages were classified as members of the 936 type based on a generated fragment size that was shown to be identical to that obtained using a control 936-type phage and different from control phages of the c2 and P335 types (Labrie and Moineau, 2000; Figure 4).

\section{Phage Host-Range Determination}

To determine the host range of the 20 phages isolated in this study, phages were propagated and a host
A

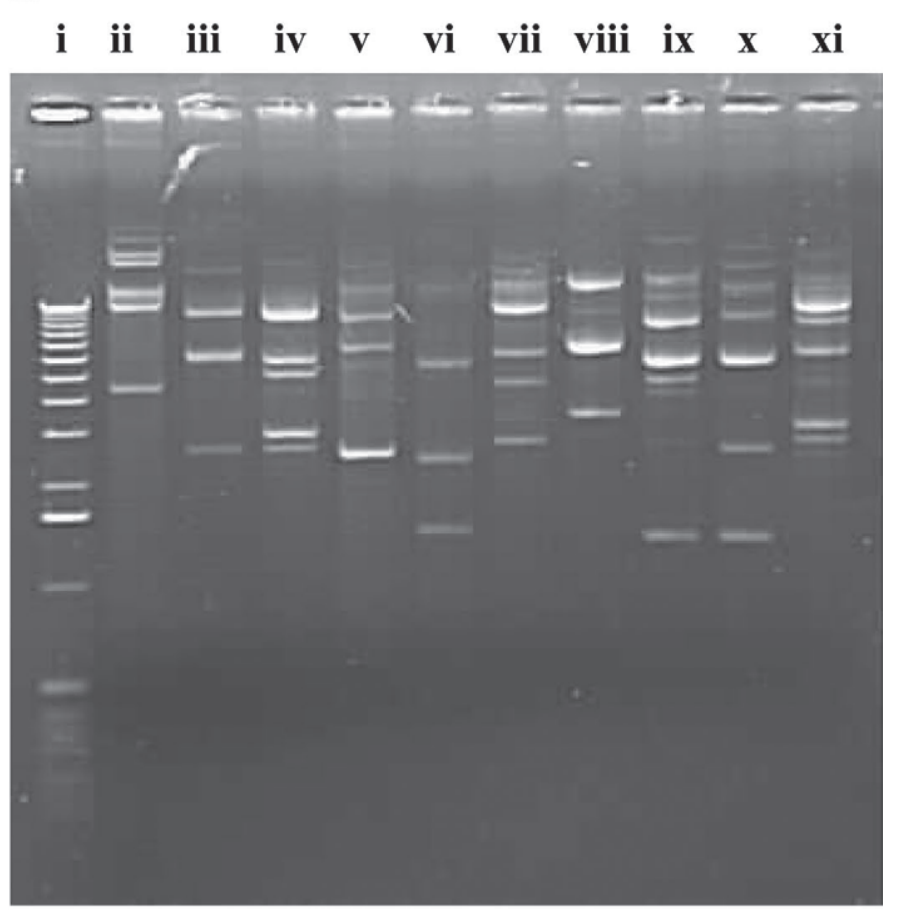

B

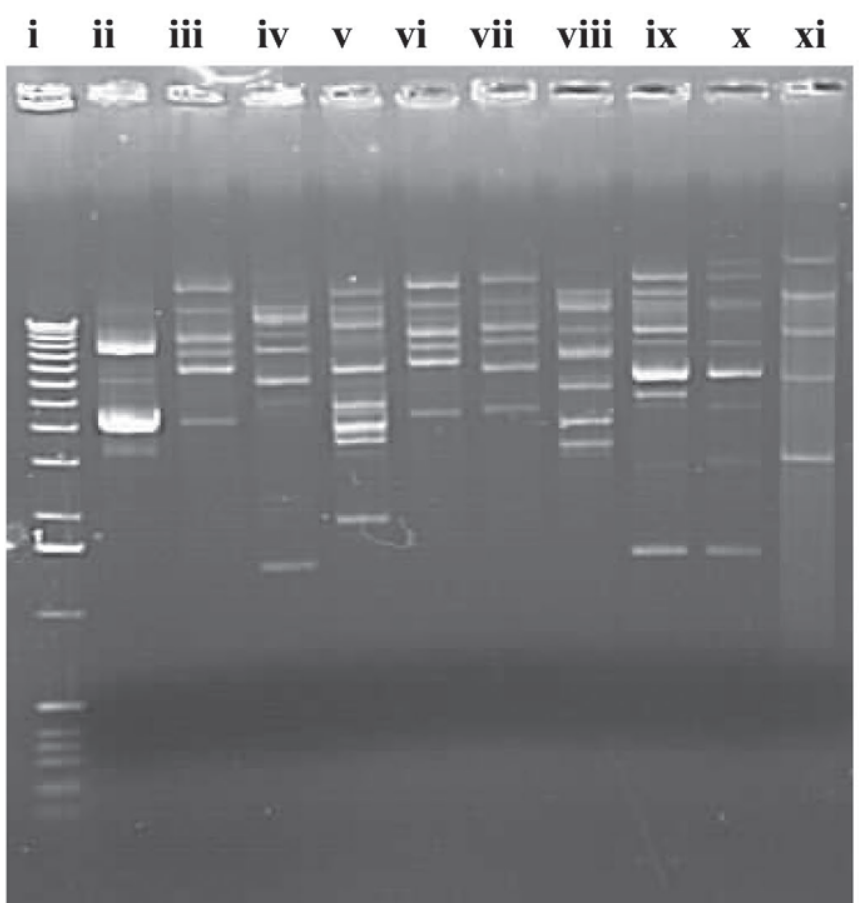

Figure 1. (A) Representative plasmid profiles of lactococcal strains isolated from starter mixture (SM) 2 (1 to 20). Lane $\mathrm{i}=$ molecular weight marker X (Roche Diagnostics Corp., Indianapolis, IN). Lane ii to $\mathrm{xi}=\mathrm{SM} 1$, SM 2, SM 3, SM 4, SM 5, SM 6, SM 7, SM 8, SM 9, SM 10. (B) Representative plasmid profiles of lactococcal strains isolated from SM1 (A to T). Lane $\mathrm{i}=$ molecular weight marker X; lanes ii to $x i=$ SM B, SM D, SM E, SM H, SM I, SM J, SM K, SM L, SM M, and SM D. 


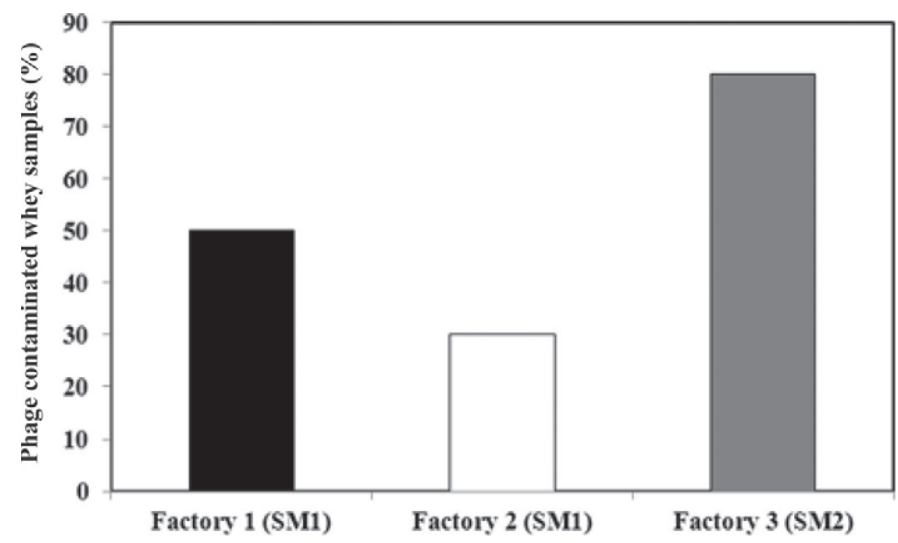

Figure 2. Proportion (\%) of whey samples from the 3 factories that contained phages. screening was performed in duplicate on the 40 starter strains that had been isolated from the undefined starter cultures SM1 and SM2. Host-range analysis showed that the majority of phages were able to cross infect L. lactis ssp. lactis, ssp. cremoris, and ssp. lactis biovar diacetylactis (Table 3). Phages PhiJF1, PhiLcj, and PhiG did not infect ssp. lactis biovar diacetylactis, whereas phage Phi16 infected only ssp. lactis biovar diacetylactis strains $\mathrm{SM}$ 8, SM 9, SM E, SM L, and SM M [as well as strain ML8 (ssp. lactis) from the UCC culture collection, see below]. Twenty-two of the 40 strains from the SM1 and SM2 starter culture mixes were found to be susceptible to phages, whereas the remaining 18 strains did not exhibit any sensitivity to these phages (and are therefore not included in Table 3). To assess the infectivity of the 20 phages against starter strains not used in either the SM1 or the SM2

A
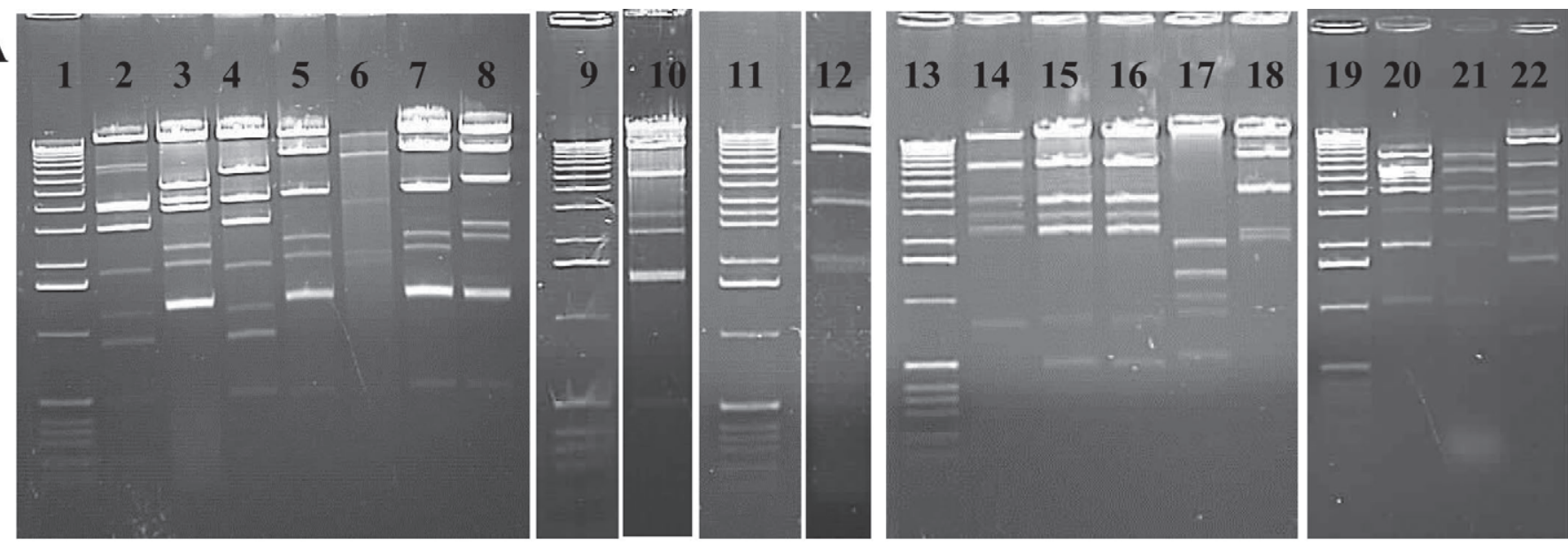

B
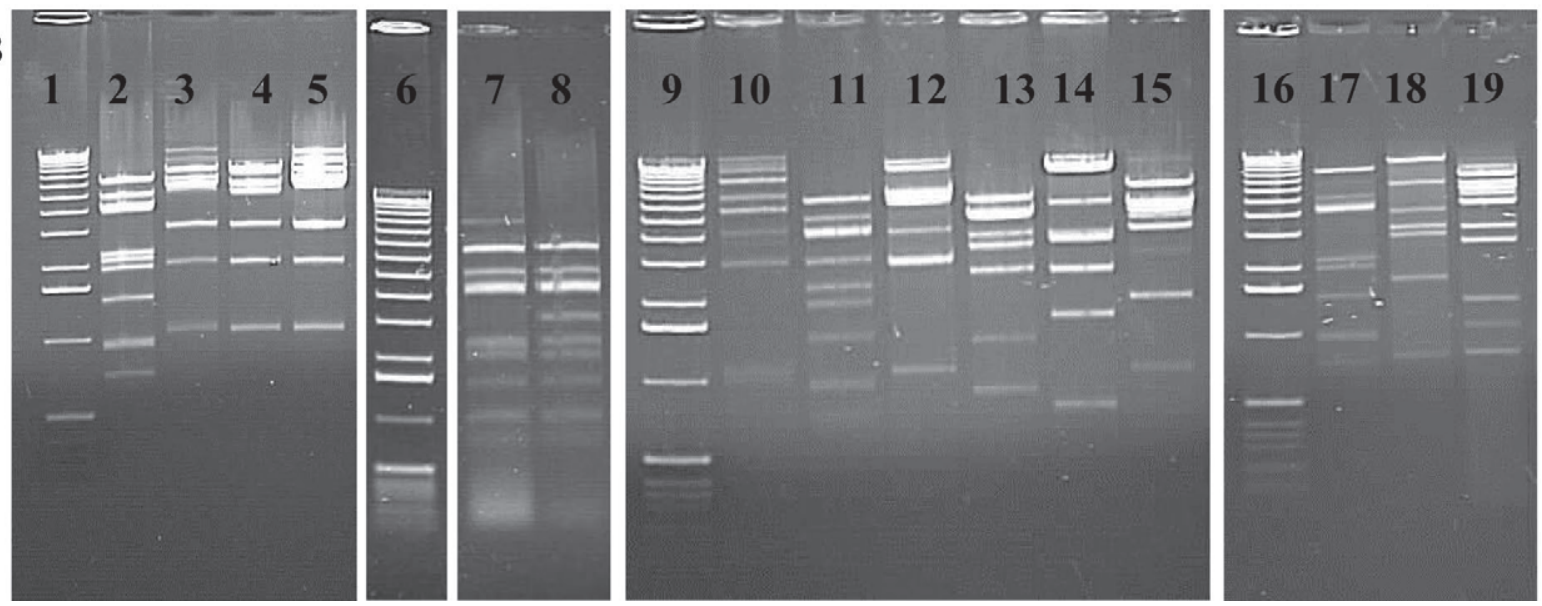

Figure 3. Representative restriction profiles of phages isolated from lactococcal whey samples cut with EcoR1. (A) Lanes 1,9 11, 13 , and 19 = molecular weight marker X (Roche Diagnostics Corp., Indianapolis, IN); lanes 2 to 8 = Phi 15, Phi121, Phi114, Phi16, Phi92, Phi40, and Phi93; lanes 10 and 12 = Phi17 and Phi19; lanes 14 to $18=$ Phi G, Phi 44, Phi JF1, PhiLcj, and PhiLj; lanes 20 to $22=$ Phi145, Phi109, and Phi4 cut with EcoRI. (B) Representative restriction profiles of phages isolated from lactococcal whey samples cut with EcoRV. Lanes 1, 6, 9, and $16=$ molecular weight marker X; lanes 2 to $5=$ Phi114, Phi16, Phi93, and Phi40; lanes 7 to $8=$ Phi144, and Phi 15 ; lanes 10 to $15=$ Phi G, Phi 44, Phi JF1, PhiLcj, PhiLj, and Phi 145 cut with EcoRV; lanes 17 to $19=$ Phi 109, Phi 4, and Phi 121 cut with EcoRV. 


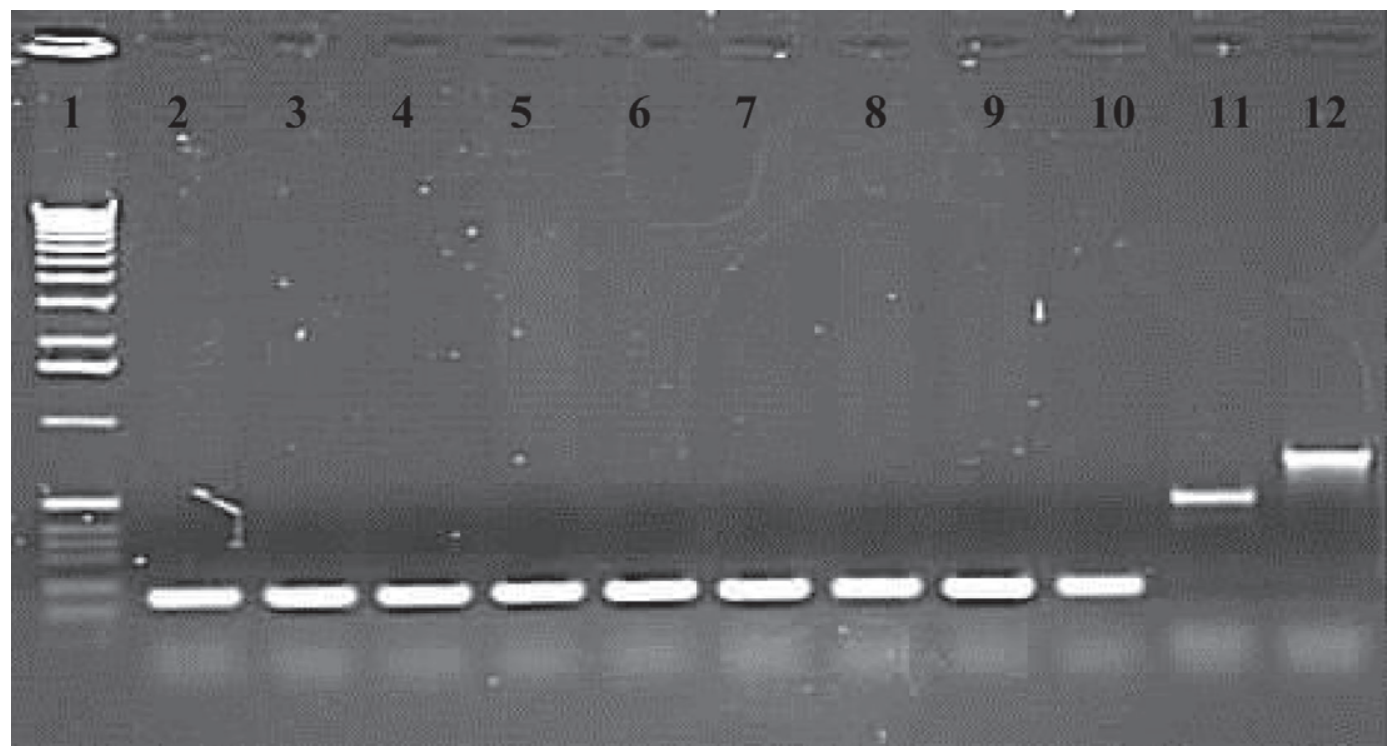

Figure 4. Representative multiplex PCR of phages isolated from lactococcal whey samples. Lane $1=$ molecular weight marker X (Roche Diagnostics Corp., Indianapolis, IN); lanes 2 to 9 = Phi16, PhiG, Phi129, Phi 145, Phi109, Phi4, Phi93, Phi114; lane $10=$ biL66 (936-type); lane $11=\mathrm{C} 2$ (c2-type); and lane $12=$ Tuc2009 (P335-type).

starter mixture, spot assays were also performed using 30 lactococcal strains from the UCC strain collection as potential hosts (representing various starter and laboratory strains). Two lactococcal strains were found to be sensitive to some of the phage isolates: phages Phi129, Phi43, Phi93, PhiLcj, Phi109, and Phi40 had the ability to infect L. lactis ssp. cremoris W34 (isolated from a Danish starter culture), whereas Phi17, PhiG, and
Phi16 were shown to infect L. lactis ssp. lactis ML8 (a starter culture from the United Kingdom).

\section{Electron Microscopy}

All isolated phages were further analyzed using transmission electron microscopy. The 20 phages displayed a typical Siphoviridae phage morphology of an isometric

Table 2. Characteristics of phage isolated from dairy whey

\begin{tabular}{|c|c|c|c|c|c|c|c|}
\hline \multirow[b]{2}{*}{ Phage } & \multirow[b]{2}{*}{ Source/factory } & \multirow[b]{2}{*}{ Species } & \multicolumn{2}{|c|}{ Electron microscopy } & \multirow[b]{2}{*}{$\begin{array}{l}\text { Estimated } \\
\text { genome size } \\
(\mathrm{kb})\end{array}$} & \multicolumn{2}{|c|}{ Plaque morphology } \\
\hline & & & $\begin{array}{l}\text { Tail } \\
(\mathrm{nm})\end{array}$ & $\begin{array}{l}\mathrm{NPS}^{1} \\
(+/-)\end{array}$ & & $\begin{array}{l}\text { Diameter } \\
\text { (mm) }\end{array}$ & $\begin{array}{l}\mathrm{Halo}^{2} \\
(\mathrm{~mm})\end{array}$ \\
\hline Phi43 & 1 & 936 & 151 & + & 31.1 & $2-3$ & 1 \\
\hline Phi19 & 1 & 936 & 152 & - & 28.44 & $2-3$ & - \\
\hline Phi4 & 1 & 936 & 130 & + & 29.9 & $2-3$ & 0.5 \\
\hline Phi17 & 1 & 936 & 165 & - & 30.4 & 3 & - \\
\hline PhiJF1 & 1 & 936 & 144 & - & 26.7 & 3 & - \\
\hline PhiLcj & 1 & 936 & 165 & + & 26.9 & 2 & 1 \\
\hline PhiG & 1 & 936 & 145 & + & 32.4 & 2 & 0.5 \\
\hline Phi109 & 2 & 936 & 130 & + & 30.2 & 3 & 1 \\
\hline Phi93 & 2 & 936 & 161 & - & 31.28 & 2 & - \\
\hline Phi129 & 2 & 936 & 150 & - & 28.26 & 2 & 0.5 \\
\hline Phi121 & 2 & 936 & 162 & + & 27.2 & 2 & 1 \\
\hline Phi92 & 2 & 936 & 150 & - & 29 & 3 & - \\
\hline PhiLj & 2 & 936 & 150 & + & 26.9 & 3 & 1 \\
\hline Phi155 & 3 & 936 & 150 & + & 29 & $1-2$ & - \\
\hline Phi16 & 3 & 936 & 165 & - & 29.9 & $3-4$ & 1 \\
\hline Phi44 & 3 & 936 & 138 & + & 26.3 & $3-4$ & - \\
\hline Phi114 & 3 & 936 & 160 & + & 26.9 & 3 & - \\
\hline Phi15 & 3 & 936 & 140 & + & 30 & 4 & 1 \\
\hline Phi40 & 3 & 936 & 165 & - & 31.8 & 2 & - \\
\hline Phi145 & 3 & 936 & 164 & - & 29.1 & $2-3$ & - \\
\hline
\end{tabular}

${ }^{1}$ Neck passage structure.

${ }^{2}$ Presence of additional zone of lysis around the primary plaque. 
capsid and a long, noncontractile, striated tail and were classified into the 936-type phage group (Figure $5)$. Characteristics of each phage are summarized in Table 2. Several phages (Phi155, Phi109, Phi43, Phi4, PhiLcj, PhiLj, PhiG Phi44, Phi15, and Phi121) were found to display a neck passage structure (NPS) between the protein capsid and tail (Figure 5). Phages Phi4, Phi121, PhiLj, and PhiG were found to display unique long whisker-like projections ending in small terminal knots extending from the neck collar (Figure 5 ; panels $3,11,13$, and 7). Among the phages isolated in this study, Phi15, Phi44, and Phi114 displayed what appeared to be a double-disk NPS between its capsid and tail (Figure 5; panels 18, 16, and 17).

\section{DISCUSSION}

Many of the previous studies on dairy phage biodiversity have focused on a large number of dairy facilities across an extensive geographical range. These include Australia (8 dairy factories, several states, starter rotational strategy; Castro-Nallar et al., 2012), the Republic of Belarus (21 dairy factories, 6 regions; Raiski and Belyasova, 2009), Germany (several dairy facilities; Atamer et al., 2009), and Norway (8 dairy factories, spread across Norway, bulk starter; Kleppen et al., 2011). To the best of our knowledge, this is the first publication describing the biodiversity of lactococcal phages in dairy facilities producing Gouda-type cheese in central Europe. Furthermore, whereas previous studies have looked at specific individual cheese factories (Rousseau and Moineau, 2009), this is the first large-scale study of the prevalence of phage against 2 undefined starter cultures. Biodiversity studies as described here are essential to any facility that carries out cheese production with undefined starters with a large, but unknown number of lactococcal strains. As a result, certain starter strains may be under significant pressure from phage attack, which may not be apparent because phage-insensitive strains in the starter mix will still be able to achieve milk acidification. As the product-specific technological properties (such as flavor compounds, exopolysaccharide production, texture characteristics) contributed by individual strains within the mix is unknown, the true effect of phage infection would not be apparent until the final, matured product is complete. The phage-mediated elimination of certain strains in the mixed culture may therefore result in a poorer and inconsistent quality of the final product, which is a potential drawback to the use of mixed starter cultures.

The proportion of whey samples that tested positive for phages against SM1 (50\% factory 1, 30\% factory 2) was lower than that obtained for SM2 (80\%, factory 3), which may indicate that the SM2 mixed starter culture is more frequently subjected to phage attack and that potentially a greater number of phage-sensitive strains exist within SM2 that were not isolated in this study. However, it should be noted that the true number of individual strains in each starter mixture is probably higher and that additional phages may therefore have been present in the whey samples. From the phagepositive whey samples, 20 genetically distinct lactococcal phages were isolated from 156 whey samples collected from 3 facilities manufacturing Gouda-type cheese in the 2009-2010 production year. Consistent with previous lactococcal dairy phage ecology studies (Szczepanska et al., 2007; Atamer et al., 2009; Rousseau and Moineau, 2009), the 936-type phage emerged as a dominant species. Surprisingly, no members of other lactococcal phage species were isolated during the screening process, a finding only demonstrated previously in 2 studies (Josephsen et al., 1999; Rousseau and Moineau, 2009). This may be due to the fact that a single cheese type is being produced, unlike a previous study that was carried out on a variety of dairy products and that revealed the presence of members of the c2- and P335-type phages (Raiski and Belyasova, 2009). Similar to our study, Kleppen et al. (2011) isolated only 936-type phages during the production of a Dutch-type cheese, which may indicate that the dominance of a single phage species may be due in part to the dairy product being manufactured or other starter cultures used.

All 20 of the phages isolated in this study had genome sizes (between 26 and $31 \mathrm{~kb}$ ) within the expected range of the 936 species as demonstrated by phage restriction profiles. Phi109, Phi114, and Phi15 produced the same restriction pattern when digested with EcoRI, yet differed in their EcoRV-generated pattern, although they exhibited a similar host range, which may indicate that these phages are closely related (Figure $3 \mathrm{~A}$ and $\mathrm{B}$ ). Other examples like this were observed in our work, showing that distinction of phages should not rely on a single observation but must be made based on differences seen in both host range and DNA restriction patterns.

The 20 phages were confirmed to be of the 936 type by PCR and displayed a morphological appearance typical of the 936-type phage (Dupont et al., 2004). They differed morphologically from each other only in the presence or absence of an NPS and in slightly varying tail lengths. Previously isolated 936-type phages such as biBB29, bil170, Sk1, and P2 were shown to lack an NPS (Mahony et al., 2006; Hejnowicz et al., 2009), although more recently characterized 936-type phages, such as those identified in this study as well as Canadian isolates (CB13, CB14, CB19, and CB20) and 
Table 3. Host range of isolated phages

\begin{tabular}{|c|c|c|c|c|c|c|c|c|c|c|c|c|c|c|c|c|c|c|c|c|c|c|c|c|}
\hline \multirow[b]{2}{*}{ Phage } & \multicolumn{24}{|c|}{ Strain } \\
\hline & 1 & 5 & 7 & 8 & 9 & 11 & 13 & 15 & 16 & 18 & 19 & $\mathrm{~A}$ & $\mathrm{D}$ & $\mathrm{E}$ & $\mathrm{F}$ & G & $\mathrm{H}$ & I & $\mathrm{J}$ & $\mathrm{L}$ & M & $\mathrm{N}$ & W $34^{1}$ & ML $8^{1}$ \\
\hline Phi43 & + & - & + & - & - & - & - & - & - & - & - & - & + & - & - & - & - & + & + & + & + & + & + & - \\
\hline Phi19 & + & + & - & - & + & - & - & + & - & - & - & + & - & + & - & - & - & - & - & + & + & - & - & - \\
\hline Phi4 & - & - & - & - & - & - & + & + & - & - & - & + & - & + & + & - & - & - & - & + & + & - & - & - \\
\hline Phi17 & - & - & - & + & + & - & - & - & + & - & - & + & - & + & - & - & - & - & - & + & + & - & - & + \\
\hline PhiJF1 & - & - & - & - & - & - & - & - & - & - & - & + & - & - & + & + & + & - & - & - & - & - & - & - \\
\hline PhiLcj & - & - & - & - & - & - & - & - & - & - & - & + & + & - & - & - & - & + & + & - & - & - & + & - \\
\hline $\mathrm{PhiG}$ & - & - & - & - & - & - & - & - & - & - & - & - & - & - & + & + & + & - & - & - & - & - & - & + \\
\hline Phi109 & - & + & + & - & - & + & + & + & - & - & + & - & + & + & - & - & - & - & + & - & + & - & + & - \\
\hline Phi93 & + & + & - & - & - & - & - & + & - & - & - & + & + & + & - & - & - & - & + & + & + & - & + & - \\
\hline Phi129 & + & + & - & - & - & - & - & - & - & - & + & - & + & - & + & - & - & - & - & - & + & + & + & - \\
\hline Phi121 & - & - & + & - & + & + & + & + & + & - & - & + & - & + & - & - & - & - & - & + & + & - & - & - \\
\hline Phi92 & - & - & + & - & - & - & - & + & - & - & - & + & - & - & - & - & - & - & - & - & - & - & - & - \\
\hline PhiLj & - & - & - & - & + & + & + & + & + & - & + & + & - & - & - & - & - & - & - & + & - & - & - & - \\
\hline Phi155 & - & - & + & - & - & - & - & + & - & - & - & - & + & + & - & - & - & + & + & + & + & - & - & - \\
\hline Phi16 & - & - & - & + & + & - & - & - & - & - & - & - & - & + & - & - & - & - & - & + & + & - & - & + \\
\hline Phi44 & - & - & + & - & - & + & + & + & - & + & + & - & - & + & - & - & - & - & - & + & + & - & - & - \\
\hline Phi114 & - & - & + & - & + & + & + & + & - & + & + & - & - & - & - & - & - & - & - & - & - & - & - & - \\
\hline Phi15 & - & - & + & - & + & + & + & + & - & + & + & - & - & + & - & - & - & - & - & + & + & - & - & - \\
\hline Phi40 & - & - & - & + & + & - & + & - & + & - & + & - & - & + & - & - & - & - & - & + & + & - & + & - \\
\hline Phi145 & - & + & - & - & + & - & - & - & + & - & + & - & - & + & - & - & - & - & - & + & + & - & - & - \\
\hline
\end{tabular}

Strains from the University College Cork (Cork, Ireland) culture collection sensitive to phage isolate. 


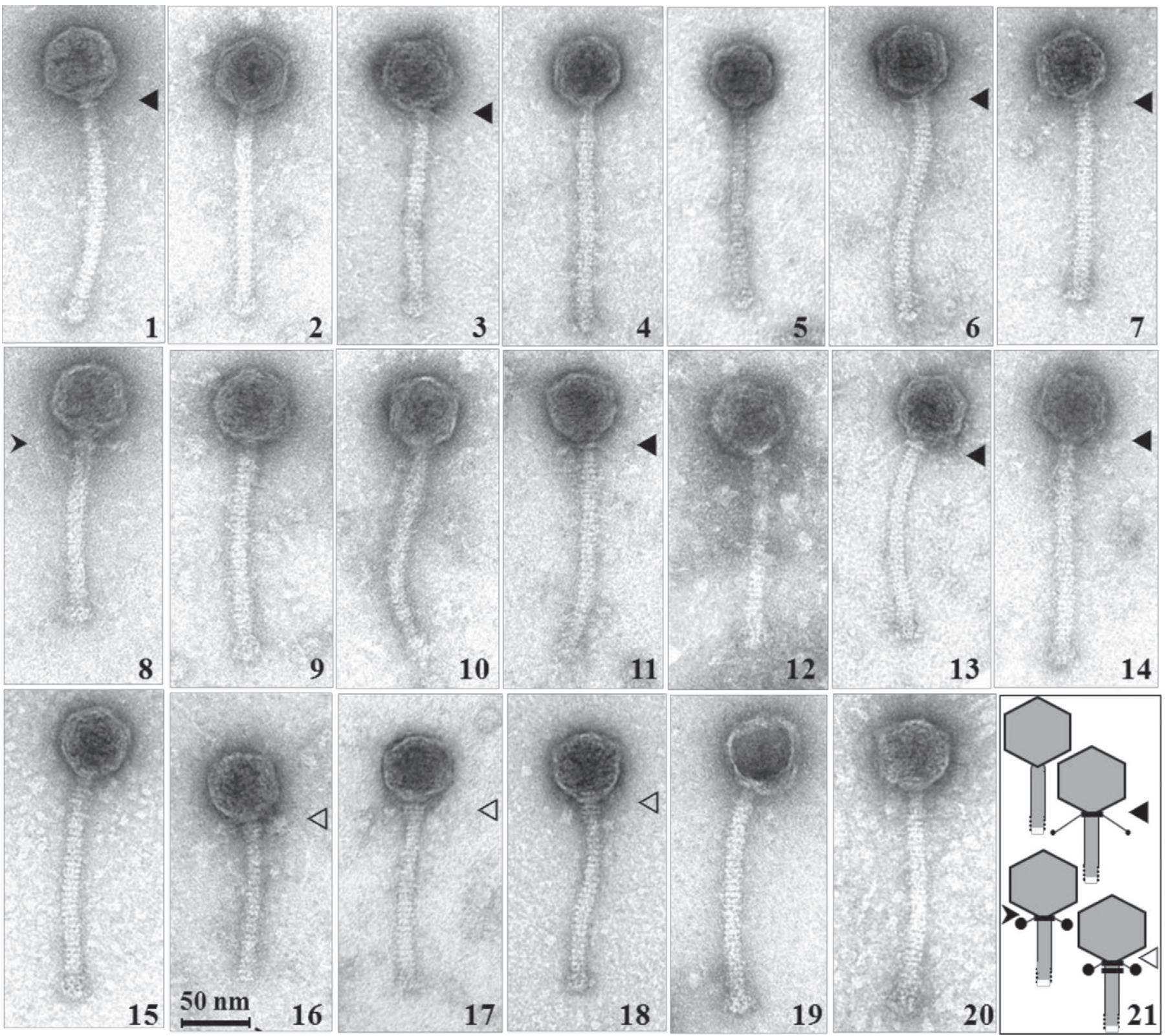

Figure 5. Representative transmission electron micrographs of isolated phages Phi43 (1), Phi19 (2), Phi4 (3), Phi17 (4), PhiJF1 (5), PhiLcj (6), PhiG (7), Phi109 (8), Phi93 (9), Phi129 (10), Phi121 (11), Phi92 (12), PhiLj (13), Phi155 (14), Phi16 (15), Phi44 (16), Phi114 (17), Phi15 (18), Phi40 (19), and Phi145 (20). Schematic representation of the phenotypic features displayed by the phage isolates (21): Phages with single neck passage structure (NPS) with long whiskers and small terminal knots (४); a phage with single NPS with short whiskers terminating in large terminal knots (arrowhead); phages with double NPS with short whiskers terminating in large terminal knots $(\triangleleft)$; phages not labeled do not possess NPS structures. Phages are shown at identical magnifications (see 50-nm size bar).

a large collection of Australian isolates, were shown to have an NPS on the basis of both phenotype and genotype (Rousseau and Moineau, 2009; Castro-Nallar et al., 2012). It appears that the newly emerging 936-type phage isolates have evolved to produce this additional structural feature. This indicates that the addition of an NPS may be advantageous, perhaps enhancing the 936type phage host range or adaptation (Crutz-Le Coq et al., 2006), thus explaining its dominance in the tested dairy environment. However, how the NPS achieves this is currently unknown. Phi4, Phi121, PhiLj, and PhiG were found to have a unique NPS with the addition of a long, whisker-like structure ending with small terminal knots (Figure 5), a morphology previously seen in the P335-type phages Tuc2009 and TP901-1 (Mc Grath et al., 2006; Bebeacua et al., 2013). How- 
$\mathbf{A}$

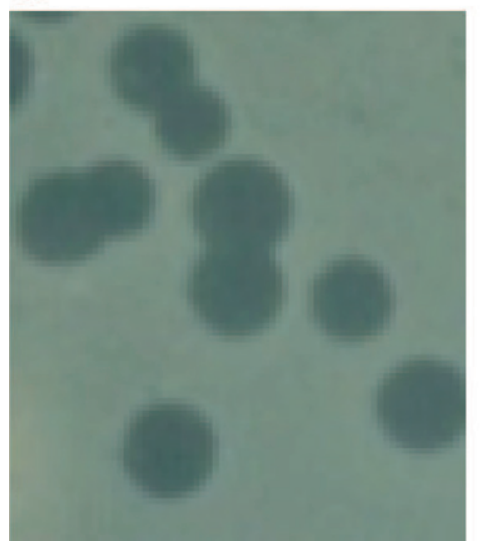

B

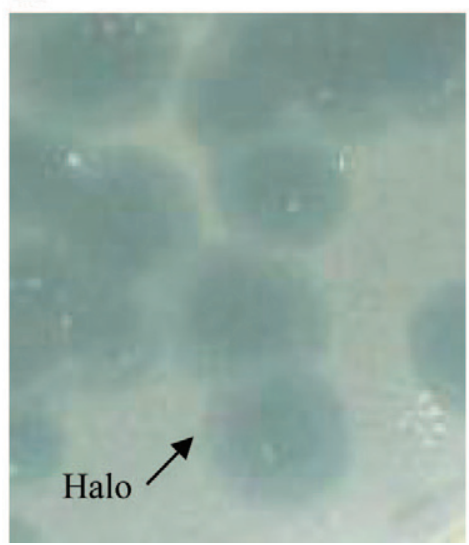

C

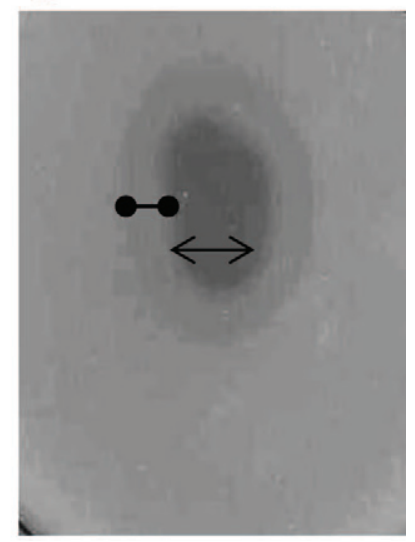

Figure 6. Isolated phage plaque morphologies: (A) Phi114 infecting host A with clear plaque; (B) Phi15 infecting host 13 with plaque surrounded by halo indicating additional cell lysis; (C) PhiLj spot assay: $\leftrightarrow=$ plaque; $-\bullet=$ zone of lysis.

ever, the benefit of such a whisker-like structure, if any, in 936-type phages is not known. Furthermore, it has been demonstrated previously that these whiskers do not appear to affect phage assembly or host range (Obregon et al., 2003; Mills et al., 2011). Phi109 displayed short whiskers ending in terminal knot (Figure 5), a morphology observed in the P335-type phage (Labrie et al., 2008). Phages Phi15, Phi114, and Phi44 were found to have a double-disk NPS (Figure 5), the role of which is currently unknown and has not been reported previously. Furthermore, phages possessing a double NPS were only isolated from factory 3 , which used a different starter mixture from both factories 1 and 2 .

With several exceptions, the phages identified here were found to exhibit a broad host range within the SM1 and SM2 starter mixtures. They were shown to infect up to 10 of the 22 strains found to be susceptible to phage infection. However, the phages from this study were limited to infecting bacterial strains isolated from SM1 and SM2, and 2 UCC culture collection strains, W34 and ML8. Furthermore, all phages were found to cross-infect strains isolated from the 2 starter mixes (as represented by strains 1 to 20 and A to T) with the exception of PhiG, Phi16, PhiLcj, and PhiJF1, which displayed a more narrow host range compared with the other isolated phages and were limited to strains from SM1. It has previously been shown that 936-type phages can be grouped based on host range and receptor binding proteins, with phages being broadly divided into 6 groups (Dupont et al., 2005), and where the majority of 936-type phages were restricted to infect either $L$. lactis ssp. cremoris or L. lactis ssp. lactis. However, the current study clearly shows that the 936-type phages can cross-infect L. lactis ssp. lactis, L. lactis ssp. cremoris, and L. lactis ssp. lactis biovar diacetylactis, thus exhibiting a more dynamic host range. Furthermore, from the results presented in Table 3 , it can be deduced that isolates form clusters based on host range, such as Phi44, Phi15, Phi114, and Phi40, as well as Phi121 and PhiLj, an observation also found in Australian 936-type phages (Castro-Nallar et al., 2012). The phages displayed similar plaque morphologies of 2 to $4 \mathrm{~mm}$, with several phages found to produce an additional zone of lysis around the primary plaque (Figure 6; Table 2). Although the molecular nature of the 936-type phage interaction with host cells is relatively undetermined, studies have shown that the interaction is dependent on a cell envelope-derived saccharide (Tremblay et al., 2006; Chapot-Chartier et al., 2010; Shepherd et al., 2011), which suggests that the bacterial cultures in the above starter mixes share a common receptor for the phage present.

\section{CONCLUSIONS}

It is evident from this study that the 936-type species continue to dominate the lactococcal dairy industry, as shown by the isolation of a diverse population of 936type phages. A diverse group of phages has been isolated from this particular fermentation facility, several with unique morphological structures (NPS and whiskers). The use of a mixed dairy starter system with at least 20 different strains may provide a melting pot of genetic material to be exchanged between hosts and phages. Further genetic analysis of these phages will provide a more comprehensive insight into the diversity and the evolutionary basis for 936-type phages isolated in this study, but also for the 936-type species as a whole.

\section{ACKNOWLEDGMENTS}

Starter strain RIK10 was a gift from Jan Kok (University of Groningen, Groningen, the Netherlands). D. 
van Sinderen is the recipient of a Science Foundation Ireland (SFI) Principal Investigator award (Ref. No. 08/IN.1/B1909). J. Murphy is the recipient of an Irish Research Council Enterprise Partnership Scheme postgraduate scholarship.

\section{REFERENCES}

Atamer, Z., J. Dietrich, M. Müller-Merbach, H. Neve, K. J. Heller, and J. Hinrichs. 2009. Screening for and characterization of Lactococcus lactis bacteriophages with high thermal resistance. Int. Dairy J. 19:228-235.

Atamer, Z., and J. Hinrichs. 2009. Thermal inactivation of the heatresistant Lactococcus lactis bacteriophage P680 in modern cheese processing. Int. Dairy J. 20:163-168.

Bebeacua, C., L. Lai, C. S. Vegge, L. Brondsted, M. van Heel, D. Veesler, and C. Cambillau. 2013. Visualizing a complete Siphoviridae member by single-particle electron microscopy: The structure of lactococcal phage TP901-1. J. Virol. 87:1061-1068.

Braun, J. V., S. Hertwig, H. Neve, A. Geis, and M. Teuber. 1989. Taxonomic differentiation of bacteriophages of Lactococcus lactis by electron microscopy, DNA-DNA hybridization, and protein profiles. J. Gen. Microbiol 135:2551-2560.

Capra, M. L., H. Neve, P. C. Sorati, Z. Atamer, J. Hinrichs, K. J. Heller, and A. Quiberoni. 2013. Extreme thermal resistance of phages isolated from dairy samples: Updating traditional phage detection methodologies. Int. Dairy J. 30:59-63.

Casey, C. N., E. Morgan, C. Daly, and G. F. Fitzgerald. 1993. Characterization and classification of virulent lactococcal bacteriophages isolated from a Cheddar cheese plant. J. Appl. Microbiol. 74:268 275

Castro-Nallar, E., H. Chen, S. Gladman, S. C. Moore, T. Seemann, I. B. Powell, A. Hillier, K. A. Crandall, and P. S. Chandry. 2012 Population genomics and phylogeography of an Australian dairy factory derived lytic bacteriophage. Genome Biol. Evol. 4:382393.

Chapot-Chartier, M. P., E. Vinogradov, I. Sadovskaya, G. Andre, M. Y. Mistou, P. Trieu-Cuot, S. Furlan, E. Bidnenko, P. Courtin, C. Pechoux, P. Hols, Y. F. Dufrene, and S. Kulakauskas. 2010. Cell surface of Lactococcus lactis is covered by a protective polysaccharide pellicle. J. Biol. Chem. 285:10464-10471.

Chomczynski, P., and N. Sacchi. 1987. Single-step method of RNA isolation by acid guanidinium thiocyanate-phenol-chloroform extraction. Anal. Biochem. 162:156-159.

Chopin, A., M. C. Chopin, A. Moillo-Batt, and P. Langella. 1984. Two plasmid-determined restriction and modification systems in Streptococcus lactis. Plasmid 11:260-263.

Crutz-Le Coq, A. M., F. Cantele, S. Lanzavecchia, and S. Marco. 2006 Insights into structural proteins of 936-type virulent lactococcal bacteriophages. Arch. Virol. 151:1039-1053.

Deveau, H., S. J. Labrie, M. C. Chopin, and S. Moineau. 2006. Biodiversity and classification of lactococcal phages. Appl. Environ. Microbiol. 72:4338-4346.

Dupont, K., F. K. Vogensen, and J. Josephsen. 2005. Detection of lactococcal 936-species bacteriophages in whey by magnetic capture hybridization PCR targeting a variable region of receptor-binding protein genes. J. Appl. Microbiol. 98:1001-1009.

Dupont, K., F. K. Vogensen, H. Neve, J. Bresciani, and J. Josephsen. 2004. Identification of the receptor-binding protein in 936-species lactococcal bacteriophages. Appl. Environ. Microbiol. 70:5818 5824 .

Eller, M. R., R. S. Dias, C. A. De Moraes, A. F. De Carvalho, L. L. Oliveira, E. A. Silva, C. C. da Silva, and S. O. De Paula. 2012. Molecular characterization of a new lytic bacteriophage isolated from cheese whey. Arch. Virol. 157:2265-2272.

Emond, E., and S. Moineau. 2007. Bacteriophages and food fermentations. Pages 93-124 in Bacteriophage: Genetics and Molecular Biology. Scientific Press/Caister Academic Press, Norfolk, UK.
Garvey, P., D. v. Sinderen, D. P. Twomey, C. Hill, and G. F. Fitzgerald. 1995. Molecular genetics of bacteriophages and natural phage defense systems in the genus Lactococcus. Int. Dairy J. 5:905-947.

Gasson, M. J. 1983. Plasmid complements of Streptococcus lactis NCDO 712 and other lactic streptococci after protoplast-induced curing. J. Bacteriol. 154:1-9.

Guglielmotti, D. M., D. J. Mercanti, J. A. Reinheimer, and L. Quiberoni Adel. 2011. Review: Efficiency of physical and chemical treatments on the inactivation of dairy bacteriophages. Front Microbiol 2:282.

Harrigan, W. F. 1998. Laboratory Methods in Food Microbiology. 3rd ed. Academic Press/Gulf Professional Publishing, San Diego, CA.

Hejnowicz, M. S., M. Golebiewski, and J. Bardowski. 2009. Analysis of the complete genome sequence of the lactococcal bacteriophage bIBB29. Int. J. Food Microbiol. 131:52-61.

Hussain, K., T. Masud, S. Maqsud, and T. Mahmood. 2008. Characterization of Lactococcus phages from Dahi whey. Pak. J. Nutr. 75:689-694.

Josephsen, J., P. Petersen, H. Neve, and E. W. Nielsen. 1999. Development of lytic Lactococcus lactis bacteriophages in a Cheddar cheese plant. Int. J. Food Microbiol. 50:163-171.

Kenny, J. G., S. Leach, A. B. de la Hoz, G. Venema, J. Kok, G. F Fitzgerald, A. Nauta, J. C. Alonso, and D. van Sinderen. 2006. Characterization of the lytic-lysogenic switch of the lactococcal bacteriophage Tuc2009. Virology 347:434-446.

Kleppen, H. P., T. Bang, I. F. Nes, and H. Holo. 2011. Bacteriophages in milk fermentations: Diversity fluctuations of normal and failed fermentations. Int. Dairy J. 21:592-600.

Labrie, S., and S. Moineau. 2000. Multiplex PCR for detection and identification of lactococcal bacteriophages. Appl. Environ. Microbiol. 66:987-994.

Labrie, S. J., J. Josephsen, H. Neve, F. K. Vogensen, and S. Moineau. 2008. Morphology, genome sequence, and structural proteome of type phage P335 from Lactococcus lactis. Appl. Environ. Microbiol. 74:4636-4644.

Lillehaug, D. 1997. An improved plaque assay for poor plaque-producing temperate lactococcal bacteriophages. J. Appl. Microbiol. 83:85-90.

Lubbers, M. W., N. R. Waterfield, T. P. Beresford, R. W. Le Page, and A. W. Jarvis. 1995. Sequencing and analysis of the prolateheaded lactococcal bacteriophage $\mathrm{c} 2$ genome and identification of the structural genes. Appl. Environ. Microbiol. 61:4348-4356.

Mahony, J., H. Deveau, S. Mc Grath, M. Ventura, C. Canchaya, S. Moineau, G. F. Fitzgerald, and D. van Sinderen. 2006. Sequence and comparative genomic analysis of lactococcal bacteriophages jj50, 712 and P008: Evolutionary insights into the 936 phage species. FEMS Microbiol. Lett. 261:253-261.

Mahony, J., J. Murphy, and D. van Sinderen. 2012. Lactococcal 936type phages and dairy fermentation problems: From detection to evolution and prevention. Front Microbiol 3:335.

Mc Grath, S., H. Neve, J. F. Seegers, R. Eijlander, C. S. Vegge, L. Brondsted, K. J. Heller, G. F. Fitzgerald, F. K. Vogensen, and D. van Sinderen. 2006. Anatomy of a lactococcal phage tail. J. Bacteriol. 188:3972-3982.

Miklič, A., and I. Rogelj. 2003. Characterization of lactococcal bacteriophages isolated from Slovenian dairies. Int. J. Food Sci. Technol. 38:305-311.

Mills, S., C. Griffin, O. O'Sullivan, A. Coffey, O. E. McAuliffe, W. C. Meijer, L. M. Serrano, and P. R. Ross. 2011. A new phage on the Mozzarella block: Bacteriophage 5093 shares a low level of homology with other Streptococcus thermophilus phages. Int. Dairy J. 21:963-969.

Moineau, S., J. Fortier, H. W. Ackermann, and S. Pandian. 1992. Characterization of lactococcal bacteriophages from Quebec cheese plants. Can. J. Microbiol. 38:875-882.

Müller-Merbach, M., H. Neve, and J. Hinrichs. 2005. Kinetics of the thermal inactivation of the Lactococcus lactis bacteriophage P008. J. Dairy Res. 72:281-286.

Obregón, V., J. L. Garcia, E. Garcia, R. Lopez, and P. Garcia. 2003. Genome organization and molecular analysis of the temperate 
bacteriophage MM1 of Streptococcus pneumoniae. J. Bacteriol. $185: 2362-2368$.

Pillidge, C. J., and A. W. Jarvis. 1988. DNA restriction maps and classification of the lactococcal bacteriophages $\mathrm{c} 2$ and sk1. J. Dairy Sci. Technol. 23:411-416.

Quiberoni, A., D. M. Guglielmotti, and J. A. Reinheimer. 2003. Inactivation of Lactobacillus delbrueckii bacteriophages by heat and biocides. Int. J. Food Microbiol. 84:51-62.

Raiski, A., and N. Belyasova. 2009. Biodiversity of Lactococcus lactis bacteriophages in the Republic of Belarus. Int. J. Food Microbiol. 130:1-5.

Reddy, P. S., S. Nair, G. Mallikarjuna, T. Kaul, G. Markandeya, S. K. Sopory, and M. K. Reddy. 2008. A high-throughput, low-cost method for the preparation of "sequencing-ready" phage DNA template. Anal. Biochem. 376:258-261.

Rousseau, G. M., and S. Moineau. 2009. Evolution of Lactococcus lactis phages within a cheese factory. Appl. Environ. Microbiol. 75:5336-5344.

Shepherd, D. A., D. Veesler, J. Lichiere, A. E. Ashcroft, and C. Cambillau. 2011. Unraveling lactococcal phage baseplate assembly by mass spectrometry. Mol. Cell. Proteomics 10:M111009787.

Sing, W. D., and T. R. Klaenhammer. 1993. A strategy for rotation of different bacteriophage defenses in a lactococcal single-strain starter culture system. Appl. Environ. Microbiol. 59:365-372.
Szczepańska, A. K., M. S. Hejnowicz, P. Kolakowski, and J. Bardowski. 2007. Biodiversity of Lactococcus lactis bacteriophages in Polish dairy environment. Acta Biochim. Pol. 54:151-158.

Tremblay, D. M., M. Tegoni, S. Spinelli, V. Campanacci, S. Blangy, C. Huyghe, A. Desmyter, S. Labrie, S. Moineau, and C. Cambillau. 2006. Receptor-binding protein of Lactococcus lactis phages: Identification and characterization of the saccharide receptor-binding site. J. Bacteriol. 188:2400-2410.

Vegge, C. S., F. K. Vogensen, S. Mc Grath, H. Neve, D. van Sinderen, and L. Brondsted. 2006. Identification of the lower baseplate protein as the antireceptor of the temperate lactococcal bacteriophages TP901-1 and Tuc2009. J. Bacteriol. 188:55-63.

Verreault, D., L. Gendron, G. M. Rousseau, M. Veillette, D. Masse, W G. Lindsley, S. Moineau, and C. Duchaine. 2011. Detection of airborne lactococcal bacteriophages in cheese manufacturing plants. Appl. Environ. Microbiol. 77:491-497.

Wegmann, U., M. O'Connell-Motherway, A. Zomer, G. Buist, C. Shearman, C. Canchaya, M. Ventura, A. Goesmann, M. J. Gasson, O. P. Kuipers, D. van Sinderen, and J. Kok. 2007. Complete genome sequence of the prototype lactic acid bacterium Lactococcus lactis ssp. cremoris MG1363. J. Bacteriol. 189:3256-3270.

Whitehead, H. R., and G. A. Cox. 1935. The occurrence of bacteriophage in cultures of lactic streptococci. N.Z. J. Sci. Technol. 16:319-320. 